\title{
Prolapse of the small bowel through perforated uterus following an unsafe abortion - A case report
}

\author{
Sulaniya Chandrakanta, Mehta Seema, Meena M. L., Sulaniya P. K., \\ Deptt of Obstetrics \& Gynaecology, Mahila Chikitsalya, SMS Medical College, Jaipur, Rajasthan.
}

\begin{abstract}
Dilatation and curettage $(D \& C)$ sometimes causes uterine perforation. Unsafe abortions performed by unskilled persons, may further complicate the condition. Here we report a case of small intestinal prolapse through uterine perforation caused by $D \& C$, requiring intestinal resection. D\&C was performed by an unskilled person. As it was a 2nd trimester abortion (3 and $1 / 2$ month amenorrhea), bony part of foetus (foetal skeleton) was left in the uterine cavity. Further attempt to remove the foetus resulted into uterine perforation and intestines were prolapsed through it. Laprotomy was performed, major part of gangrenous small intestine was resected and anastomosis done. This was one of the rarest to rare life threatening complication of an unsafe abortion. Only few cases are reported in literature so far and none from Rajasthan.
\end{abstract}

Key words: Prolapsed Bowel, Uterine Perforation, Unsafe Abortion.

\section{Introduction:}

WHO defines unsafe abortion as procedure for terminating an unintended pregnancy either by an untrained personnel or in an environment that does not confirm the minimum medical standards, or both. ${ }^{[1]}$ WHO reports that in developed regions, nearly all abortions (92\%) are safe, where as developing countries more than half (55\%) are unsafe. According to WHO statistic, the risk rate for unsafe abortion is 1/270; according to majority of other sources, unsafe abortion is responsible for one in eight maternal death in India. ${ }^{[1]}$ Most of these events remain concealed initially, there by further complicating the scenario Here we are reporting a rare case of uterine perforation with prolapse of small intestine, following second trimester abortion, by unqualified person.

\section{Case report:}

A 35 year old lady G4P3 was admitted in emergency ward in department of obstetrics and gynaecology SMS hospital with the complaint of pain and distended abdomen and bleeding per vaginum. She was referred to institute after an unsafe abortion by an untrained person. She had amenorrhea $3 \& 1 / 2$ months, which was terminated by untrained Dai in a remote village .After termination, she had continuous bleeding per vaginum and developed acute pain and distended abdomen .On examination patient was conscious \& well oriented to time place and person. She was pale, afebrile with pulse $96 /$ minute, respiratory rate $18 /$ minute \& BP $110 / 70 \mathrm{~mm}$ of Hg. Per abdominal examination revealed generalised soft distension with tenderness \& muscle guarding. Bowel sounds were absent. On per vaginal examination loops of intestines were present in vagina coming out through cervical os. Os was 2 finger dilated. Uterus was 12-14weeks size \& soft in consistency and was tender. Bleeding was present. After all preliminary preparations patient was taken for laprotomy. There was a rent on the anterior wall of the uterus about $2-3 \mathrm{~cm}$ in size. Through which loops of small bowel were entering in the uterine cavity same pulled out. About $2 \& 1 / 2$ feet ileum was stripped of mesentery \& was devitalised. Resection of gangrenous bowel was done followed by ileo-ileal end to end anastomosis. Washing of abdominal cavity with saline supplemented with antiseptic (Povidine Iodine) solution was done. Uterine cavity explored digitally through the rent. Few product of conception removed. Rent repaired \& hemostasis attained. Abdominal drain placed \& abdomen closed in layers. Post operative period was uneventful.

\section{Discussion:}

According to world health organization, in every 8 minutes a women in one of the developing nation die of complications arising from unsafe abortion, making it one of the leading cause of maternal mortality $(13 \%) .{ }^{1}$ It is one of the highly neglected problems of health care in developing countries. In India it accounts for $41.9 \%$ of the maternal deaths. ${ }^{2}$ Uterine perforation and bowel injuries are the major complication of unsafe abortion .The reason of these complications is that most abortions are done by untrained personnel i.e. unskilled workers in very unhygienic conditions. ${ }^{3}$ The same happened with this unfortunate woman. The person doing the evacuation could not recognise that she had perforated the uterus and what she was pulling out was intestines. Patient has lost major part of her small intestine. Uterine perforation, bleeding, injury to bladder and bowel, sepsis, shock and death are the immediate complications of unsafe abortion. 
In our case unskilled instrumentation likely perforated the anterior wall of the uterus, through which small intestine pulled in to the uterine cavity. However patient's condition was relatively stable, hemoperitonium was absent. And the absence of other visceral injury favoured the prognosis of this woman. Unsafe abortion has also been associated with long term complications like vesico-vaginal fistula, recto-vaginal fistula, bowel, chronic pelvic inflammatory disease and infertility.

Lack of education, social stigma and other barriers to safe abortion, forces a woman to seek abortion in secrecy at high cost, leaving the poorest, least educated woman to unskilled person.

\section{Conclusion}

To reduce the morbidity and mortality associated with unsafe abortions all government and nongovernment institutions should intensively disseminate health education, information and awareness regarding unsafe abortion at all the levels. . Regular training courses for traditional birth attendants, nurses and doctors under the supervision of expert obstetrician should be carried out and post abortal family planning counselling should be the part of service. If any complication happens timely referral is very important. By creating awareness and availability of contraceptives we can reduce the incidence of unsafe abortion.

Consent: Informed consent is obtained and pt anonymity is preserved.

\section{References:}

[1]. Bhattacharyya S K, Saha S P, Bhattacharya S, Pal R. Consequences of unsafe abortion in India- a case report. Proceeding in obstetrics and gynaecology, 2011 November; 2(2):12

[2]. Singh R, Tandon I, Sujata. Vagino-peritoneal fistula a rare complication of unsafe abortion- a case report: J Obstet Gynecol India Vol.59,No.3:May/June 2009:253-254.

[3]. Kaniz Z N and Muhammad M E. The horror of unsafe abortion: case report of a life threatening complication in a 29 years old woman. Patient safety in Surgery 2013; 7:33

[4]. Agrawal R, Radika AG, radhakrishnan faeces per vaginum; A Combined gut \&uterus complication of unsafe abortion. J.Obstet Gynacol Index. 2013 March ,April;

Image 1: prolapse of small bowl through uterine perforation

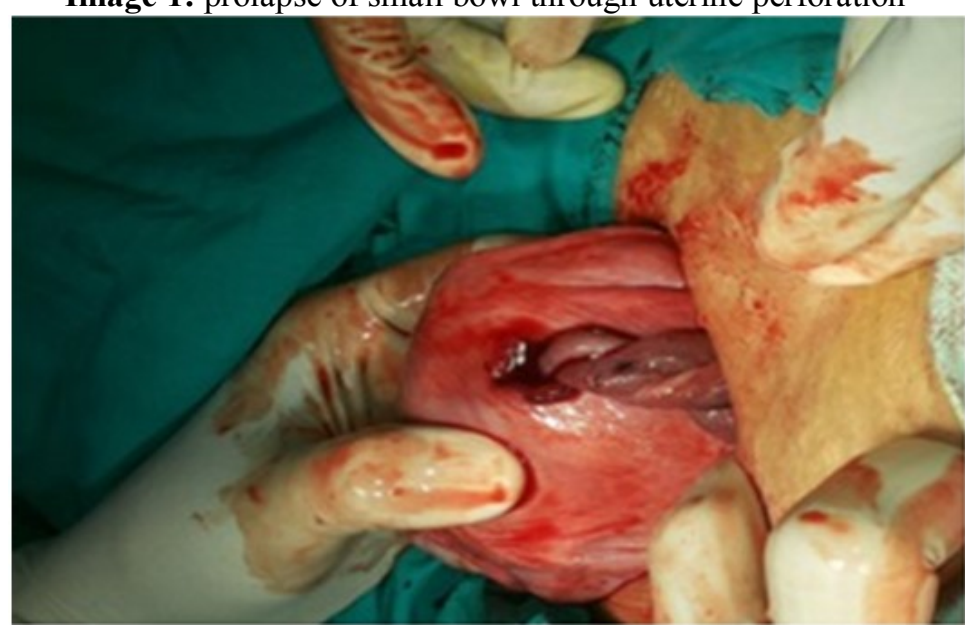

Image 2: foetal skeleton

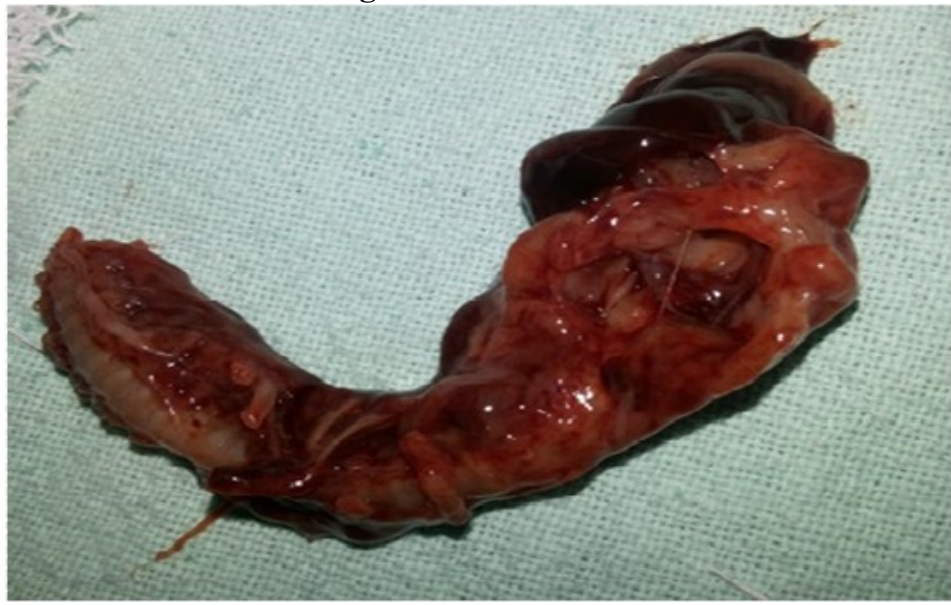


Image 3: Necrosed small bowel

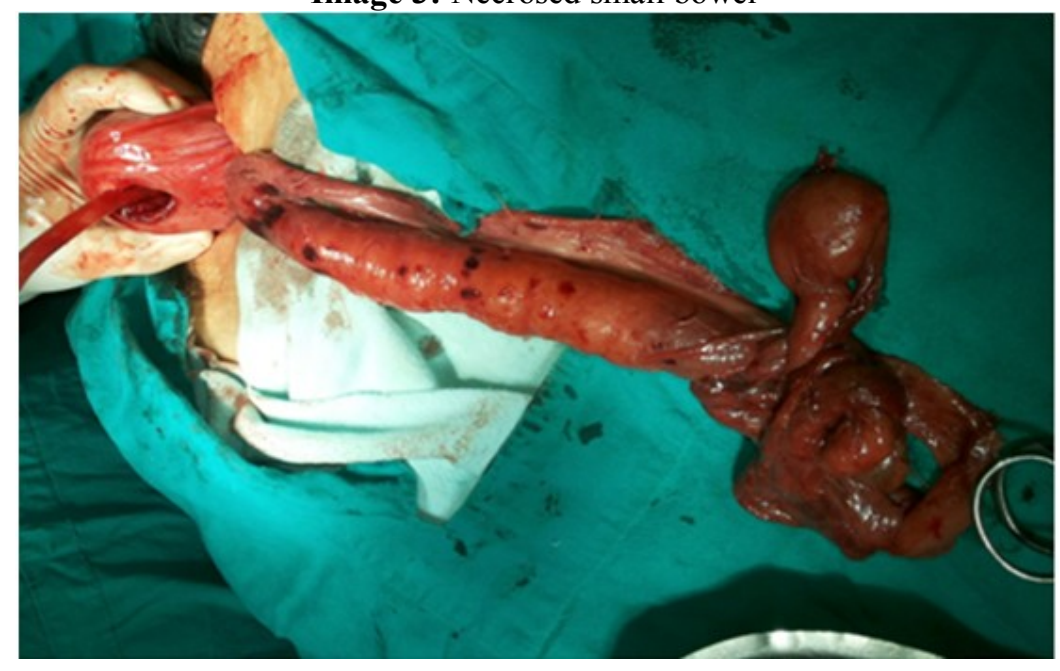

Image 4: repair- resection and end to end anastomosis of small bowel

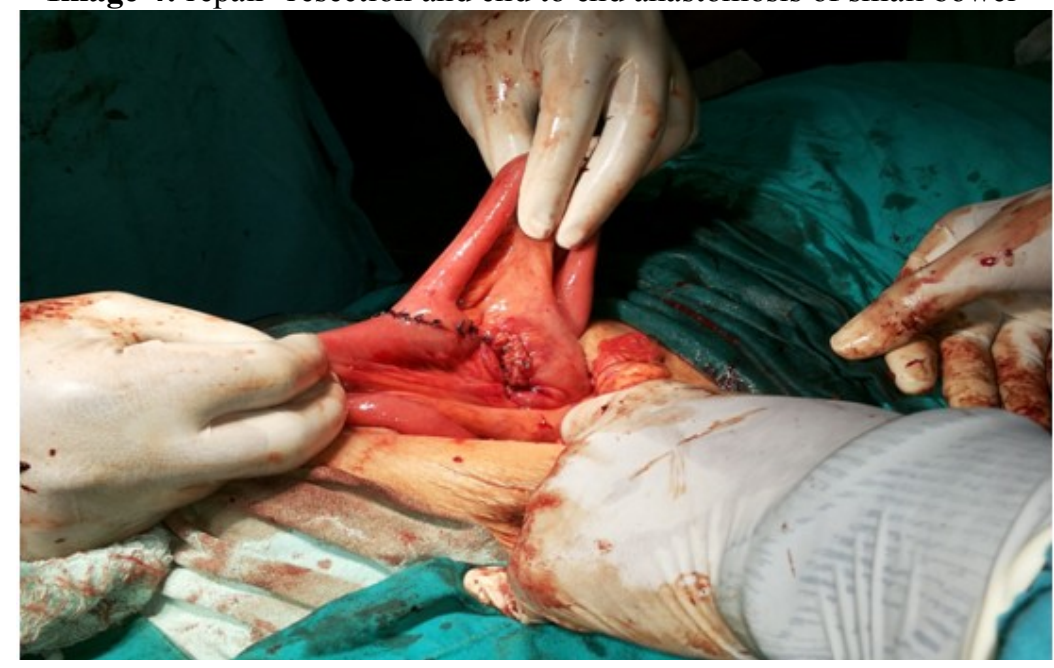

